\title{
Pobreza, Vulnerabilidade e Desenvolvimento no Território Rural Zona Sul: o que aponta o Índice de Condição de Vida?1
}

\author{
Camila Horst Toigo 2 e Marcelo Antonio Conterato ${ }^{3}$
}

\begin{abstract}
Resumo: O artigo apresenta a construção do Índice de Condição de Vida (ICV), baseado na Abordagem das Capacitações e na Abordagem dos Meios de Vida, e sua aplicação no Território Rural Zona Sul do Rio Grande do Sul. A pesquisa buscou refletir sobre a existência (ou não) de situações concretas ou potenciais de vulnerabilidade e pobreza. Para isto, foram analisados os resultados, por indicadores e por instância, auferidos pelo ICV no Território Rural Zona Sul do Rio Grande do Sul. Os resultados apontaram, então, que as famílias não estavam expostas, a priori, às situações de vulnerabilidade e pobreza. Porém, dada a existência comprovada de privações para o alcance de um maior nível de bem-estar, questionou-se sobre uma possível situação de acomodação resignada na qual essas famílias poderiam estar imersas.
\end{abstract}

Palavras-chaves: Desenvolvimento humano, pobreza, vulnerabilidade, ruralidade.

Abstract: The paper presents the Living Conditions Index's construction (LCI), based on the Capability Approach and on the Livelihoods Approach, and its application in Territorio Rural Zona Sul do Rio Grande do Sul. The research sought to reflect about the existence (or not) of concrete or potential situations of vulnerability and poverty. For this, the ICV's results were analysed by indicators and by instances. The results showed that families were not exposed, a priori, to situations of vulnerability and poverty. However, given the proven existence of privations to achieve a higher welfare level, a question was made about a possible situation of resignedly accommodation within which these families could be immersed.

Key-words: Human development, poverty, vulnerability, rurality.

DOI - http://dx.doi.org/10.1590/1234-56781806-94790550204

Classificação JEL: P25.

1. Data de submissão: 27 de abril de 2016. Data de aceite: 19 de fevereiro de 2017.

2. Pontifícia Universidade Católica do Rio Grande do Sul. Porto Alegre, Rio Grande do Sul, Brasil. E-mail: camilahorstoigo@gmail.com

3. Universidade Federal do Rio Grande do Sul. Porto Alegre, Rio Grande do Sul, Brasil. E-mail: marcelo.conterato@ufrgs.br 


\section{Introdução}

Ao indagar o modelo que propõe o desenvolvimento com olhares voltados para indicadores essencialmente econômicos arquiteta-se um questionamento, o qual é o pilar da obra de Sen: "qual é a validade de um modelo de desenvolvimento, baseado na riqueza econômica, que não se reflete nas condições objetivas de vida das populações?" (RAMBO et al., 2012, p. 7). A partir dessa reflexão, portanto, e inspirado em alguns aspectos da Abordagem das Capacitações de Amartya Sen e da Abordagem dos Meios de Vida de Frank Ellis, foi criado o Índice de Condições de Vida (ICV) pelo Programa de Pós-Graduação em Desenvolvimento Rural (PGDR) da Universidade Federal do Rio Grande do Sul (UFRGS), com apoio da professora Angela Kageyama, da Universidade Estadual de Campinas (Unicamp), após demanda da Secretaria do Desenvolvimento Territorial (SDT), do Ministério do Desenvolvimento Agrário (MDA), a partir do documento "Território da Cidadania: acompanhamento, monitoramento e avaliação".

O ICV é um índice de desenvolvimento territorial que considera a dimensão humana no "processo" de desenvolvimento multidimensional. Em razão da limitação de outros índices já existentes, sobretudo o PIB, que pouco refletem sobre condições de vida e desenvolvimento humano, o ICV permite, em certo grau, captar esses elemen- tos a partir da própria percepção dos indivíduos (famílias rurais) residentes no território.

Dado seu caráter multidimensional, abrange três esferas: a) os intitulamentos (os meios para se "alcançar" o desenvolvimento) b) os elementos de conversão dos meios para os fins e c) as capacitações e funcionamentos. Permitindo uma análise múltipla do desenvolvimento, ele foi aplicado para o Território Rural Zona Sul do Rio Grande do Sul com o intuito de acompanhar as condições de vida das famílias rurais nele residentes com base nas percepções dos próprios agentes.

Assentando-se na Abordagem das Capacitações de Amartya Sen e na Abordagem dos Meios de Vida de Frank Ellis, a pesquisa objetivou analisar aspectos do desenvolvimento humano, da pobreza e da vulnerabilidade por meio de múltiplas dimensões e com base nas percepções das condições de vida dos próprios indivíduos residentes no Território Rural Zona Sul do Rio Grande do Sul, as quais foram expressas a partir dos resultados gerados pelo Índice de Condição de Vida. A importância de buscar o conhecimento acerca dessa proposta se configura em virtude da também relevância de se incorporar as dimensões de bem-estar social e condições de vida como elementos definidores e referenciais do desenvolvimento humano das regiões rurais do estado do Rio Grande do Sul, além de trazer uma nova ferramenta capaz de refletir sobre a eficiência das políticas públicas existentes no território rural. 
Trabalhos como o de Parafán e Walter (2016) também discutem o ICV como instrumento de política pública refletidor das condições de vida da população rural.

Ressalta-se, pois, que a pesquisa se assentou no uso de métodos quantitativos e de base de dados secundários elaborada por um grupo de pesquisa da Universidade Federal do Rio Grande do Sul (UFRGS), em 2010, a partir da coleta de dados via questionários para a construção do ICV. Reconhece-se certo grau de limitação na metodologia deste trabalho, sobretudo no que diz respeito ao intento de dissertar sobre condições de vida e bem-estar dos indivíduos do TZS a partir dos resultados da aplicação de questionários, os quais foram ancorados a um momento específico da coleta dos dados em campo e, por esta razão, não captaram o processo e o desencadeamento da construção do bem-estar do público-alvo, assim como os processos que os levaram a determinadas privações e obstáculos. Apesar disso, todavia, a metodologia ainda é válida para se refletir, em certo grau, como os indivíduos entrevistados percebiam os aspectos institucionais, financeiros, naturais, produtivos, culturais e os aspectos pessoais de sua família e como essas percepções puderam refletir sobre a existência de vulnerabilidades e de pobreza multidimensional dentro do escopo do desenvolvimento humano.

\section{Abordagem das capacitações e abordagem dos meios de vida: multidimensões, multicapitais e representação social}

O diálogo existente entre as abordagens das capacitações e dos meios de vida criou oportunidades de estudiosos do desenvolvimento rural rediscutirem as estratégias de combate à pobreza e as diversas formas de vulnerabilidade a partir de um ponto de vista multidimensional. Diversos estudos ocuparam-se em abordar esta temática das mais diversas formas e voltaram-se, ainda, para as questões e agentes inseridos no meio rural (DA COSTA e COSTA, 2016; MOREIRA et al., 2009; KAGEYAMA e HOFFMANN, 2006).

Notou-se que era mais importante prover aos indivíduos pobres recursos que estimulassem suas capacidades de fortalecer suas atividades e seus meios de vida do que apenas fornecê-los comida e guarnições. Assim, a relação entre a Abordagem das Capacitações e dos Meios de Vida se constituiu a partir da ideia de que a expansão das capacitações das famílias rurais podia ser realizada com base na diversificação dos meios de vida, seja a partir do domínio produtivo ou econômico (PERONDI e SCHNEIDER, 2012; SCHNEIDER e FREITAS, 2013; ELLIS, 2000).

Algumas das mais notáveis convergências dizem respeito ao conceito de "capacidades". Em conformidade com Sen (2010), este conceito é atinente à habilidade de satisfazer determinados funcionamentos - sobretudo os mais elementares, como estar nutrido, ter saúde, estar escolarizado -, que são fundamentalmente rudimentares para atender aos níveis mais básicos de qualidade de vida. Assim, Ellis (2000) constrói o conceito de meios de vida tendo por base tal definição, sobretudo com o desígnio de referir-se, segundo Pereira, Schneider e Souza (2010), às habilidades que proporcionam o desenvolvimento das potencialidades como seres humanos. Ainda, Ellis faz menção à existência de cinco tipos de capitais que norteariam os meios de vida: físico, humano, social, natural e financeiro.

Mas como, então, tais habilidades/capacidades interligam-se com os múltiplos capitais especificados por Ellis? A resposta concentra forças em um ponto fundamental: o acesso. Conforme Pereira, Souza e Schneider (2010), a habilidade de criar um conjunto de estratégias que proporcionem melhores e distintas oportunidades/facilidades de/no acesso aos distintos tipos de capitais e que consigam manobrar as privações e dificuldades existentes estimulam a capacidade (seja individual ou familiar) para alcançar as necessidades básicas de consumo.

Ellis (2000) aponta a importância para uma família ou indivíduo rural conseguir preservar e potencializar suas capacidades para diversificar 
suas estratégias e propiciar liberdades "de escolher diferentes alternativas [não apenas] de renda num portfólio variado de possibilidades" (p. 35). Somente assim se estruturarão liberdades suficientes - e, consequentemente, um conjunto capacitário abrangente - para conduzi-los a viver da melhor maneira que lhes parece, visto que o valor que se encontra na existência de um conjunto de opções é, exatamente, o "melhor uso que se pode fazer delas" (SEN, 2010, p. 106).

Para Chambers e Conway (1991),

As capacidades são tanto um fim quanto um meio dos meios de vida: um meio de vida provê a base para o aprimoramento e o exercício das capacidades (como fim) e; capacidades (como meio) habilita um meio de vida a ser adquirido (p. 5). ${ }^{4}$

Em outras palavras, os diferentes capitais facilitam o acesso à diversificação dos meios de vida. Estes, por sua vez, habilitam e proporcionam ao indivíduo a capacidade de aprimorar e auferir distintos e diversos estilos de vida, de tal maneira que possam lhes afastar de determinadas privações e de situações de vulnerabilidades.

Os "intitulamentos" e os "funcionamentos" também são conceitos inerentes à perspectiva de Ellis. Os primeiros são representados pelo conjunto de bens adquiridos por um indivíduo por meio de diversos canais legais de aquisição propiciados a ele (SEN, 2010). Conforme apontam Perondi e Schneider (2012), os intitulamentos significam, de maneira genérica, o que uma pessoa tem direito e como ela se apropria e usufrui de tais direitos para viver a vida que deseja.

Destarte, eles são afetados pelas estratégias dos meios de vida e, por consequência, pelos seus resultados (PERONDI e SCHNEIDER, 2012). Por esta razão o acesso (e também as oportunidades que o expandem) torna-se um elemento-chave tanto na posse e/ou conquista dos múltiplos capitais quanto na expansão das liberdades que

4. No original: "Capabilities are both an end and means of livelihood: a livelihood provides the support for the enhancement and exercise of capabilities (an end); and capabilities (a mean) enable a livelihoods to be gained". podem garantir diferentes tipos de direitos, oportunidades, intitulamentos e funcionamentos.

Os funcionamentos, por sua vez, representam, na abordagem de Ellis, os resultados finais: com a posse de múltiplos capitais, estimulada pela diversificação dos meios de vida, proporcionam-se capacidades (e liberdades) elementares para a elevação da qualidade de vida e do bem-estar dos indivíduos (como estar escolarizado, estar saudável, estar nutrido, ter saúde, entre outros) de modo a superar certas privações muitas vezes intrínsecas ao ambiente em que residem.

Não obstante a aproximação das abordagens seniana e de Ellis, outro elemento também se tornou peculiar na composição teórica do ICV: a percepção do público-alvo sobre suas condições de vida. A percepção dos indivíduos foi pautada no conceito de representações sociais de Moscovici (2003).

As representações sociais são como redes de interpretação que conduzem a relação, as condutas e as comunicações sociais de cada indivíduo entre si, uns com os outros e todos com o mundo. A representação é um ato de pensar que relaciona um sujeito a um determinado objeto, seja ele uma pessoa, uma "coisa", um evento (social, material, psíquico), uma ideia, uma teoria ou um fenômeno natural, podendo ser real, mítico ou imaginário (JODELET, 1989, p. 5). É a capacidade (não necessariamente consciente) de dar sentido aos objetos e às situações (MERLEAU-PONTY, 2006).

Assim, a comunicação adquire um papel elementar no processo de representação social, visto que é por meio dela que as representações entram no cotidiano dos indivíduos e tornam-se senso comum. É desta maneira que as representações se sustentam nas realidades da vida cotidiana e representam uma via importante para estabelecer os vínculos com os quais os indivíduos interligam-se uns aos outros.

Cada representação depende das relações nas quais o indivíduo apresenta para com os objetos representados. Cada indivíduo envolve-se, individual ou coletivamente, com palavras, imagens e ideias que alcançam todos os seus sentidos sem que este perceba ou saiba. É por esta razão que 
as representações estão associadas aos processos sociais que se implicam por meio das diferenças nas sociedades. (MOSCOVICI, 2003).

A apreensão da diversidade de sentidos permite compreender, dentro de uma determinada sociedade ou grupo de indivíduos, as diferenças e semelhanças a respeito de uma realidade específica. Através da comunicação, intenta-se "considerar as representações sociais como meios de recriar a realidade". Destarte, o ICV se pauta na busca pela percepção dos indivíduos com a sólida intenção de inferir o que acham, o que sentem, o que pensam, o que entendem a respeito de sua realidade de modo que a pesquisa consiga apreender, a partir das representações sociais, determinados aspectos da realidade observada.

\section{Operacionalização do índice de condições de vida}

A expressão "condições de vida" foi se popularizando mais energicamente desde a última década e foi associada, essencialmente, ao desenvolvimento humano e ao bem-estar individual e coletivo (SEN, 2010). Assim, com o objetivo de tentar operacionalizar um conceito tão abstrato, indicadores quantitativos com dotações essencialmente sociais foram surgindo em maior número e com certa urgência.

Nos últimos anos o número de trabalhos cujo foco pauta-se na vida dos indivíduos elevou-se, com destaque para os trabalhos de Andrade et al. (2006) e da Fundação João Pinheiro (1998) em parceria com o Instituto de Pesquisa Aplicada (Ipea). A pluralidade dos Índices de Condições (ICV) contribui para apreender questões muitas vezes esquecidas ou ignoradas nos debates a respeito do desenvolvimento. Sua maior relevância se estabelece em virtude do poder de comparação da dinâmica das condições de vida em momentos distintos permitindo comparar o impacto de ações que foram direcionadas para a promoção do desenvolvimento (RAMBO et al., 2012; SDT, 2007).

OÍndice de Desenvolvimento Humano(IDH), por exemplo, direciona-se para a mensuração do bem-estar e desenvolvimento. Do mesmo modo, o Índice de Desenvolvimento Socioeconômico (Idese), organizado pela Fundação de Economia e Estatística do Rio Grande do Sul, foi criado com o intento de mensurar o desenvolvimento dos municípios gaúchos (OLIVEIRA, 2013). Todavia, tanto estes quando outras demais ferramentas analíticas, como o Índice de Desenvolvimento Sustentável (IDS) - estruturado pela professora Angela Kageyama -, o Índice de Qualidade de Vida (IQV), Índice de Nível de Vida (INIVI), o World Health Organization Quality of Life Index (WHOQOL), por exemplo, embora sejam consistentes teoricamente, carregam em sua bagagem metodológica algumas limitações concernentes à sua elaboração e à sua composição, além de não considerar os fatores, as características e os efeitos do próprio desenvolvimento, como o ICV o faz.

A necessidade de dispor de um melhor acompanhamento dos Territórios Rurais e de suas dinâmicas tornou necessário o desenvolvimento de processos e ferramentas de avaliação e informação dos mesmos que fossem mais robustas. Em virtude das limitações dos índices já existentes, uma complementação foi demandada pela SDT: a criação do Índice de Condição de Vida (ICV). A partir disso, então, o ICV foi aplicado em 37 Território Rurais, incluindo o Território Zona Sul do Rio Grande do Sul, o qual é o recorte territorial abrangente neste artigo.

O ICV é composto por três instâncias em que, a cada uma, se associam oito indicadores. A elaboração de cada um deles norteou um ou mais quesitos que compuseram o questionário final. A partir dele, pretendeu-se apreender as percepções do público-alvo (as famílias em domicílios rurais) a respeito das ações articuladas no TZS que, no período de análise, poderiam refletir sobre as ações direcionadas à promoção do desenvolvimento multidimensional no território (BRASIL, 2007).

$\mathrm{O}$ universo desta pesquisa constituiu-se na população rural residentes nos 25 municípios que compõem o TZS. Como unidade amostral, foi definido o domicílio rural conforme delimita o Instituto Brasileiro de Geografia e Estatística 
(IBGE). Ressalta-se que a amostra foi composta a partir de sorteio de Setores Censitários, os quais registram não só a localização geográfica referenciada, mas também seus indivíduos, domicílios, famílias (BRASIL, 2011), e totalizou 280 domicílios.

Os questionários abrangeram questões desde o perfil da família entrevistada, da renda, da atividade produtiva exercida (se havia), das características do domicílio, até sobre a participação da família em políticas públicas e programas governamentais e sua relação com a natureza e recursos naturais. A média de membros por domicílios rurais entrevistados no TZS foi 3,5 pessoas. Apenas $25 \%$ destes domicílios eram compostos por mais de quatro membros, sendo majoritária a composição familiar de dois ou três membros.

A respeito da caracterização dos domicílios em termos de produção, a amostra abrangeu 238 famílias cuja produção assentava-se no setor agropecuário (vegetal, animal, extrativista, pesqueira, florestal, aquicultura). Assim, um número preponderante e equivalente a 189 domicílios foi identificado como domicílio de agricultura familiar e 49 domicílios (cerca de 17\%) foram identificados como não familiares. Apenas 42 famílias não participavam produtivamente deste setor, apresentando-se como domicílios de moradia e/ou lazer.

Em relação aos domicílios com produção, 233 deles (equivalente a 97,8\%) apresentaram a família trabalhando de maneira principal. De maneira prevalecente, a produção do estabelecimento era destinada à comercialização e ao consumo com expressividade de 74,64\%. Em apenas 18 domicílios $(6,42 \%)$ - que podem incluir domicílios apenas de moradia, especialmente de pessoas mais idosas - a produção destinava-se exclusivamente para o autoconsumo.

Os questionários foram aplicados em nove municípios (Aceguá, Canguçu, Cerrito, Hulha Negra, Pedro Osório, Pinheiro Machado, Piratini, Santa Vitória do Palmar e São Lourenço do Sul) abrangendo $10^{5}$ Setores Censitários. Frisa-se, portanto, que a escolha desses municípios também foi estipulada a partir da amostra aleatória com o intuito de permitir a representatividade do território (SCHNEIDER et al., 2012). Portanto, para obter o resultado final do ICV, foram calculadas as médias aritméticas dos 24 indicadores. $\mathrm{O}$ passo posterior foi calcular a média dos oito indicadores respectivos a cada instância, o qual resultou em seu valor final. O penúltimo passo foi o cálculo final do ICV.

Para tal, fez-se a média harmônica das três instâncias baseada da Equação (1) a seguir. Frisa-se que a escolha pela média harmônica não se baseou em critérios definidos e específicos; foi uma escolha do grupo que construiu o índice, já que não se pensava na existência de muitos desequilíbrios dentro das instâncias.

$$
I C V=\frac{3}{\frac{1}{d_{1}}+\frac{1}{d_{2}}+\frac{1}{d_{3}}}
$$

Devido à escala Likert, pôde-se transformar os valores finais encontrados (dos indicadores, das instâncias e do ICV final/geral da amostra) em um valor cuja amplitude variou entre 0 e 1 . A partir disso, foi estabelecido que, para valores entre 0,0 e 0,2 , o critério avaliativo seria "baixo"; para valores entre 0,2 - 0,4, o critério seria "médio baixo"; para valores entre $0,4-0,6$, o critério seria "médio"; entre os valores 0,6 - 0,8, o critério seria "médio alto"; e entre 0,8-1,0, o critério seria "alto". As representações gráficas das instâncias com seus respectivos indicadores e do próprio ICV deram-se a partir de Biogramas, as quais são imagens gráficas que, conforme Waquil et al. (2007), pode ser associado com um "gráfico de radar", em que cada dimensão está disposta em um eixo próprio e todas convergindo para um ponto central.

5. O município de Canguçu teve dois Setores Censitários sorteados. 


\section{Desenvolvimento humano, vulnerabilidade e pobreza rural no TZS: o que revela o ICV?}

Em vista de que o fácil acesso aos recursos e a possibilidade de alcançar distintos capitais são vias substanciais (porém, não únicas) para a expansão das oportunidades, a existência de certas privações que trazem obstáculos à apropriação destes elementos, reflete, sobretudo, na também privação da expansão de capacidades e liberdades elementares relacionadas ao bem-estar. Neste contexto, a criação de um portfólio de atividades e ativos/capitais que garantem a sobrevivência, a realização de funcionamentos e o avanço das condições de vida pode ser crucial para um indivíduo, família ou comunidade (SEN, 2010, 2008; ELLIS, 2000).

Com base nisto, os resultados pertencentes à primeira instância do ICV permitiram refletir a respeito dos meios para se alcançar o desenvolvimento humano no TZS, essencialmente a partir da análise do acesso (ou obstáculos ao acesso) aos capitais e recursos. Os dados - que traduziram as percepções das famílias residentes em domicílios rurais - possibilitaram, adicionalmente, desenvolver uma análise referente aos elementos que condicionaram a realização das escolhas dos indivíduos.

A Instância $1^{6}$ do índice apresentou o resultado geral mais baixo dentre as três instâncias. Com valor equivalente a 0,544, conforme explícito na Tabela 1, a seguir, recebeu um critério avaliativo "médio". Ressalta-se que esse critério foi refletido em função da existência de assimetria (ou menor harmonia) entre as respostas, as quais variaram entre o máximo e o mínimo.

Na Figura 1, a seguir, é possível observar melhor o desempenho de cada indicador do ICV a partir do seu Biograma e visualizar quais deles obtiveram melhores resultados.

6. Novamente ressalta-se que os dados consideraram apenas os domicílios que apresentaram produção agropecuária, independente do tipo de mão de obra (familiar ou não familiar)
Concernente ao capital humano representado pelos indicadores de escolaridade e moradia, um cenário promissor foi observado dadas as percepções positivas a respeito dos mesmos. Consoante à Ellis (2000), o capital humano pode ser aprimorado por investimentos e acesso à educação e profissionalização, através de habilidades adquiridas na busca por atividades diversas e por meio de cuidados à saúde, por exemplo.

A importância da escolaridade (enquanto estratégia para a reprodução social) configura-se em razão do bem coletivo essencial que possui para a promoção da cidadania e para a inserção social plena dos indivíduos. A escolaridade e, sobretudo, o fácil acesso a ela compõe-se como "a principal mediadora de oportunidades existentes nas sociedades" (IBGE, 2014, p. 100), gerando melhores alcances.

Apresentando uma percepção boa em 46,2\% dos casos (seguida pela percepção "regular" $(35,7 \%))$, o indicador referente à escolaridade apresentou-se como um dos mais importantes desta instância. Conforme Rambo et al. (2015), os indivíduos entrevistados afirmavam que, para as atividades exercidas por eles no dia-a-dia, o grau de escolaridade que obtinham era suficiente, mesmo que grande parte deles tinham o ensino fundamental incompleto. Aqui, há um paradoxo: ao mesmo tempo em que é evidente que a elevação do nível educacional da população e a maior igualdade no acesso à ela é um ativo com demasiada valia para a melhoria de vida e para a realização de diversos funcionamentos, o baixo nível de escolarização dos indivíduos rurais do TZS era suficiente para eles e não buscava ser elevado.

Na composição do ICV, as condições de moradia introduziram-se como indicador de capital humano por permitir indícios a respeito da saúde dos indivíduos relacionada à falta de sanitarismo. Desde 2002, os Fóruns Urbanos Mundiais (World Urban Forum) buscaram enfatizar a relação do bem-estar das famílias a partir da compreensão de que não apenas a casa em si merecia atenção do poder público, mas, sobretudo, a relação que esta tinha com a construção social na qual as famílias residentes estavam inseridas. 
Tabela 1. Índice de Condição de Vida e frequências - Instância 1 e indicadores

\begin{tabular}{lcc}
\hline \multicolumn{1}{c}{ Indicadores } & ICV & Frequência \\
\hline Instância 1 & 0,544 & \\
Número de famílias trabalhando & 0,577 & 238 \\
Características da mão de obra & 0,599 & 237 \\
Área utilizada para produção & 0,589 & 238 \\
Escolaridade da mão de obra & 0,618 & 238 \\
Condições de moradia & 0,638 & 238 \\
Condições de acesso aos mercados & 0,481 & 238 \\
Condições em participar de programas do governo & 0,422 & 232 \\
Condições de ter acesso ao crédito & 0,439 & 238 \\
Condições para receber assistência técnica & 0,461 & 238 \\
Presença de instituições e organizações & 0,565 & 238 \\
\hline
\end{tabular}

Nota: Mínimo: 0,000; Máximo: 1,000.

Fonte: Elaborada pela autora com base nos dados do SGE (2015).

Figura 1. Biograma da Instância 1

1.1 Número de famílias trabalhando

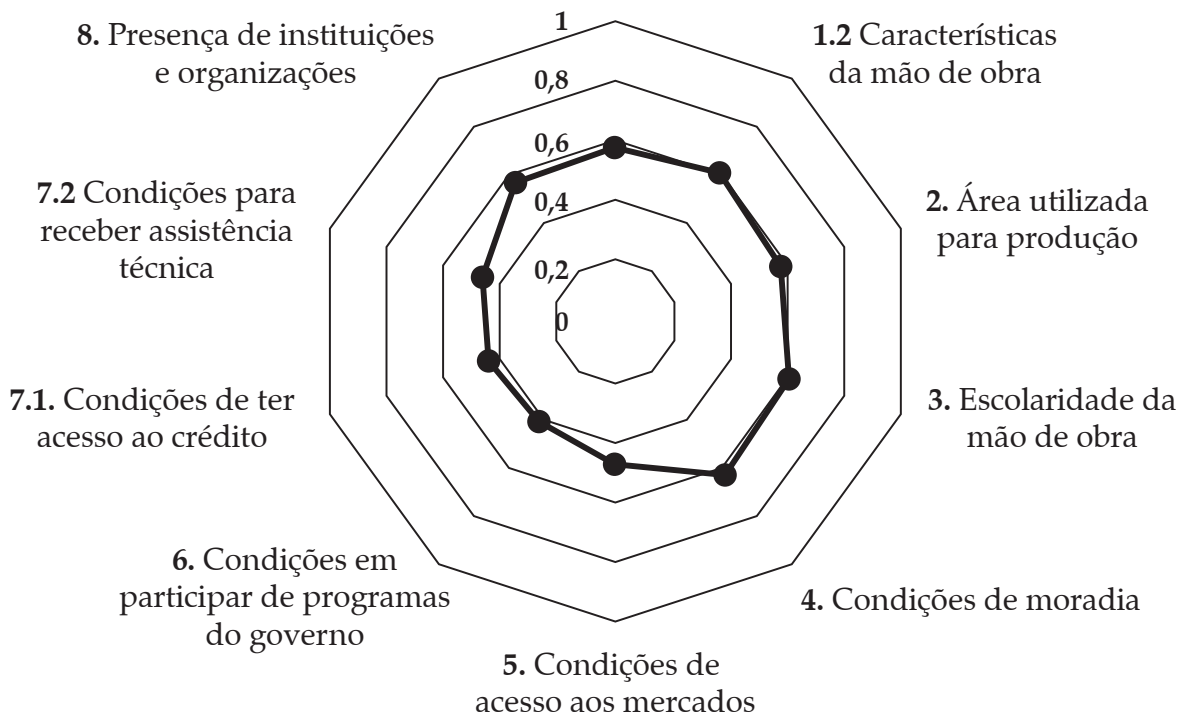

Fonte: Elaborada pela autora com base nos dados do SGE (2015).

Os resultados apontaram para um cenário mais positivo para as questões de habitação, dada a percepção majoritária de uma situação boa de moradia, visto que um número elevado de indivíduos em todo mundo (sobretudo no Brasil) tem pouco acesso aos serviços de saúde, saneamento básico, água potável e lutam constantemente para vencer a morbidez desnecessária e a morte pre- matura (SEN, 2010). Além disso, ter boas condições dentro do lar pode gerar muitas capacidades substantivas as quais podem ser potencializadas e promovidas diante dessa circunstância.

Embora esses últimos indicadores tenham refletido em percepções mais promissoras sobre as condições de vida das famílias rurais no TZS, foi detectado um cenário relacionado ao capital 
financeiro que merece destaque, essencialmente a respeito das condições de mercado, do acesso ao crédito e da (pouca) facilidade de acessar programas e políticas governamentais. Esses indicadores dizem respeito, de uma maneira geral, aos estoques de capital cujas famílias têm (ou não) acesso (ELLIS, 2000).

Quanto às condições de mercado, muito pode-se refletir sobre as condições e facilidades econômicas. Referente às condições para ir até os mercados (distância, facilidades de deslocamento), 40,3\% dos domicílios avaliaram a situação como "mais para ruim" do que para bom, indicando, assim, a existência de privações relacionadas à falta de infraestrutura, à precariedade no transporte público e/ou ao distanciamento.

O acesso ao crédito pelas famílias rurais na historicidade da economia brasileira sempre mostrou obstáculos quase insuperáveis. Nas palavras de Bianchini (2013),

Apesar de a política agrícola não excluir formalmente nenhum segmento [da população], a exclusão se dava, na prática, por diferentes níveis de procedimentos operacionais adotados pelas instituições financeiras (p. 65).

Com a criação do Pronaf, que institucionalmente constituiu-se em uma solução para a superação de alguns desses obstáculos, o acesso ao crédito passou a ser melhor remanejado e tornou possível a concessão de um volume mais expressivo de recursos. A criação de programas e políticas públicas como o Programa de Aquisição de Alimentos (PAA) e o Programa Nacional de Alimentação Escolar (PNAE), visou (além do incremento ao Pronaf) fortalecer, promover e consolidar a agricultura familiar "para um rural sustentável” (BIANCHINI, 2013, p. 68).

Foi detectada uma percepção preponderante de que as condições para acessar o crédito ou qualquer financiamento, seja formal ou informal, para a produção (mesmo que não se aproprie de linhas de crédito) eram "complicadas" ou "mais ou menos complicadas" para as famílias. Isso remete diretamente à essa discussão. Uma das limitações (que, evidentemente cau- sam privações à expansão das oportunidades) mais discutidas academicamente nas últimas décadas refere-se ao complexo e burocrático sistema bancário. Como superação desta privação, Bianchini (2013) sugeriu a criação de novas formas de financiamento que contemplassem todo o conjunto de famílias produtoras que não conseguiam se adequar a esse sistema. Para tornar isso viável, porém, torna-se relevante a prioridade de outras formas de financiamento para a agricultura, como Fundos Rotativos, Compras Antecipadas, Sistemas de Trocas, além das linhas de crédito populares, como Pronaf.

Segundo Ellis (2000), esses recursos financeiros têm papel notável na construção do portfólio de ativos e estratégias por, principalmente, converter-se em outras formas de capital (capital físico e humano, por exemplo) ou bens de consumo. Apesar de não ser o principal meio para se alcançar o bem-estar, é inegável, até mesmo para Sen (2010), que a renda e o acesso aos recursos financeiros possuem indiscutível significância para a sobrevivência das famílias e para a expansão das oportunidades e liberdades.

No que diz respeito à participação em programas governamentais e/ou políticas públicas, apenas 40 famílias indicaram a não participação, o que já mostrou um cenário menos pessimista. Todavia, concernente às 198 restantes, a percepção em relação às condições para conseguir participar de tais programas/políticas foi preponderantemente ruim, ou melhor, compreendidas como "complicadas" e "mais ou menos complicadas".

A alta burocracia constitui-se em um dos principais obstáculos à inserção das famílias rurais nas políticas e programas do governo, embora necessária para controle do uso adequado das verbas estatais. O excesso de documentação e de comprovação exigida para os beneficiários, conjuntamente com o acesso a um mercado financeiro complexo, que traz relativas dificuldades e equívocos, isola e exclui diversas pessoas (principalmente grupos minoritários) em todo o País de adequarem-se à determinadas políticas e programas que seriam sumariamente 
importantes para a melhoria de suas condições de vida.

Nas palavras de Soares (2009), quando a pobreza cai aceleradamente as políticas de transferência de renda mostram-se como as principais responsável sobre essa redução, "a definição de quais famílias deveriam ser beneficiadas por estas políticas se transforma em um debate cada vez mais relevante" (p. 7). Muitas vezes o limiar entre a inclusão e a exclusão do cidadão na política pública é tão pequeno que gera dúvidas quanto à eficiência e a justiça prezada pelo seu objetivo central.

Inerente à essa discussão está o debate a respeito dos critérios para definir a pobreza. Esses geralmente encontram-se apoiados em abordagens monetárias e de necessidades básicas trazendo, ainda, muitas contradições e diferenças entre si (COMIM e BAGOLIN, 2002; SOARES, 2009).

O próprio Brasil não contém uma linha metodológica oficial de pobreza e, por esta razão, muitas políticas públicas acabam gerando problemas. Assim,

À medida que estas políticas se tornam cada vez mais importantes, a tarefa de adotar uma linha de pobreza oficial, ou pelo menos ter um tratamento oficial para a questão, torna-se cada vez mais urgente (SOARES, 2009, p. 7).

Outro problema muito discutido academicamente é a universalização das políticas em uma sociedade altamente heterogênea. Uma política arquitetada localmente com o máximo de conhecimento por parte dos planejadores e gestores sobre o público-alvo e a localidade (isto é, assentada na coesão social), e tendo por base estudos científicos, poderia ser mais abrangente do que uma política nacional universal que não se altera conforme as particularidades de cada região e população.

Assim sendo, a percepção das famílias residentes em domicílios rurais do TZS de que o acesso às políticas públicas era complicado e dificultado salienta a urgência do Estado em rever suas ações e as (in)eficiências intrínsecas no combate à pobreza no território. Frisa-se, novamente, que a pobreza deve ser tratada de maneira multidimensional e reduzida a partir da expansão das oportunidades e liberdades.

As análises preliminares a respeito da Instância 1 do ICV para o território ressaltam que não só a capacidade de agência dos indivíduos é importante para superar vulnerabilidades e privações (SEN, 2010; ELLIS, 2000). A ação do Estado para permitir a expansão das capacidades e liberdades é indubitavelmente indispensável.

Os meios para alcançar o bem-estar, as oportunidades e liberdade elementares não estão meramente enfocados nas mercadorias e recursos disponíveis, embora, como já comentado, estes sejam relevantes. A possibilidade de realizar funcionamentos que, segundo Sen (2008), são "elementos constitutivos do bem-estar humano" (p. 36), permite a construção de leques de alternativas a partir dos quais as pessoas conseguem e podem realizar suas escolhas e viver conforme a vida que lhe é merecida. Sendo assim, estar apto para ir em busca do próprio bem-estar está relacionado com a capacidade e liberdade de realizar funcionamentos e com as oportunidades dispostas na sociedade (SEN, 2008, 2010).

A próxima análise designa inferir sobre as distintas e potenciais trajetórias do desenvolvimento humano no TZS, analisadas a partir da conversão dos intitulamentos, ativos e recursos em funcionamentos e capacitações. Apesar de ter adquirido um resultado superior ao da primeira instância (com equivalência de 0,576 de acordo com a Tabela 2), a Instância 2 também recebeu um critério avaliativo "médio". Este foi estabelecido em função da assimetria existente entre as respostas.

O Biograma ilustrado na Figura 2 indica o desempenho de cada indicador dentro da instância. Como pode ser observado, um dos piores referiu-se à renda de sustento da família que foi considerada, dominantemente, como regular. Este resultado indicou que a quantia da renda que sobrava ao pagar-se os passivos e que era apropriada de maneira finalística por essas famílias para seu próprio consumo não era suficientemente capaz de saciar todas as necessidades e vontades esperadas por elas. 
Tabela 2. Índice de Condição de Vida e frequências - Instância 2 e indicadores

\begin{tabular}{llc}
\hline \multicolumn{1}{c}{ Indicadores } & ICV & Frequência \\
\hline Instância 2 & 0,576 & \\
Situação da renda familiar & 0,504 & 238 \\
Resultado da produtividade do trabalho & 0,543 & 238 \\
Resultado da produtividade da terra & 0,599 & 238 \\
Diversificação da produção agrícola & 0,502 & 238 \\
Diversificação das fontes de renda & 0,453 & 238 \\
Conservação das fontes de água & 0,662 & 238 \\
Conservação da área de produção & 0,612 & 238 \\
Preservação da vegetação nativa & 0,734 & 238 \\
\hline
\end{tabular}

Nota: Mínimo: 0,000; Máximo: 1,000.

Fonte: Elaborada pela autora com base nos dados do SGE (2015).

Figura 2. Biograma da Instância 2

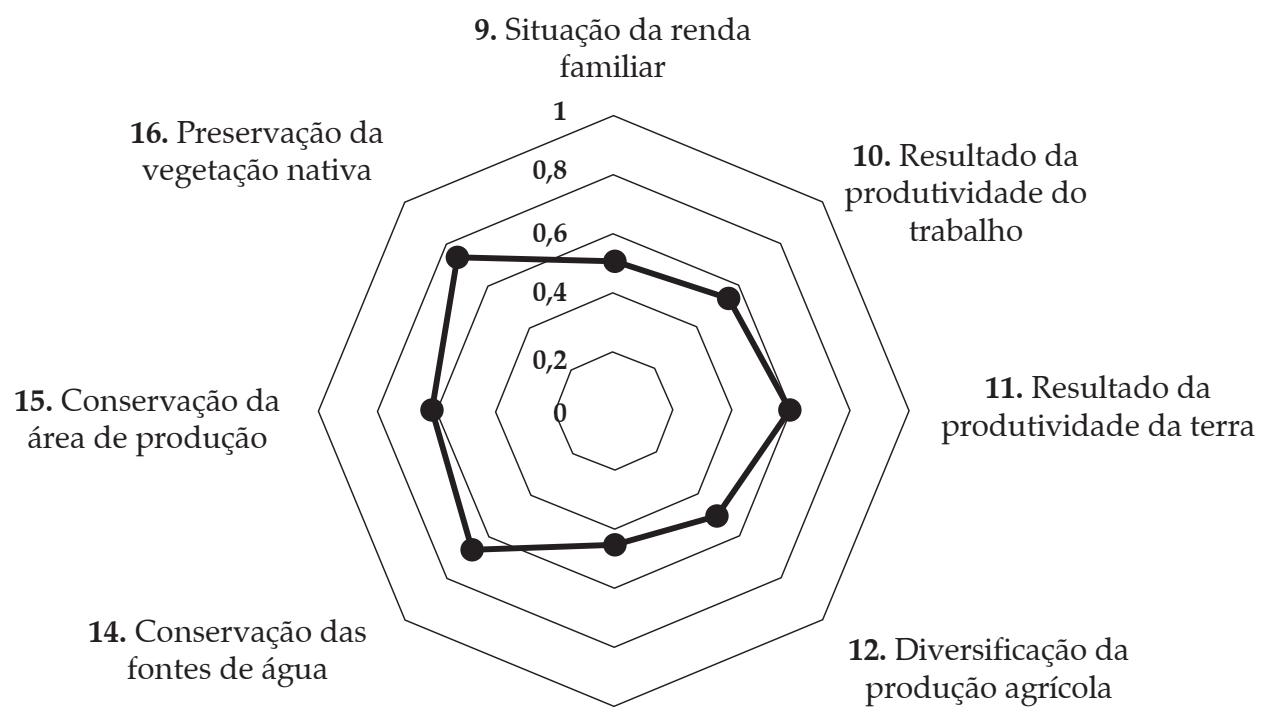

13. Diversificação das fontes de rendas

Fonte: Elaborada pela autora com base nos dados do SGE (2015).

Embora não tenha sido possível quantificar essa renda, refletiu-se que o que sobrava dava conta apenas das necessidades básicas das famílias e não permitia expandir de maneira otimizada (ou próxima a isso) o seu bem-estar. Esta circunstância pôde estar relacionada a diversos fatores como baixa diversificação das fontes de renda e das atividades e alto percentual de despesas (sobretudo aquelas ligadas às atividades produtivas) que resultaram em baixas quantias de renda de fato apropriadas dentro dos domicílios. Esses resultados deixam evidente a importância da diversificação dos meios de vida, mencionado por Ellis (2000), na sustentabilidade da reprodução social e familiar.

De uma maneira cada vez mais intensa, a diversificação das fontes de renda vem adquirindo importância dentro das unidades rurais. Conforme Kageyama (1998), as transformações e revalorizações no e do mundo rural ocorridas nas 
últimas décadas proporcionaram, além da redução do tempo destinado às atividades de produção agrícola, uma diminuição da dependência das rendas agrícola como fonte primordial de proventos.

$O$ indicador referente à diversificação das fontes de renda das famílias no TZS foi o mais baixo da Instância 2. Conforme Rambo et al. (2015), a considerável distância em relação aos centros urbanos e, principalmente, aos mercados, a baixa fertilidade dos solos, a tradição de priorizar determinada prática produtiva (como a pecuária e a produção de tabaco), a elevada participação da agroindústria e a dificuldade no acesso às políticas públicas importantes são fatores que podem ter contribuído e continuam contribuindo para a baixa diversificação das fontes de renda e da produção.

Como Perondi e Schneider (2012) salientam, a diversificação tanto do trabalho como da renda geram um estímulo de resiliência para lidar com crises, choques ou vulnerabilidades em seus diversos tipos. Por esta razão, uma baixa diversificação de renda e de atividades nos domicílios do TZS indicaram-se como privações ou obstáculos para o alcance de estratégias alternativas de sobrevivência. Reflete-se, ainda, que dadas essas circunstâncias, o portfólio disponível de capitais das famílias pode ter sido reduzido, bem como o leque de oportunidades para levar uma vida melhor.

À parte dessa análise preliminar, houve predominância de indicadores positivos relacionados ao capital natural. Os indicadores de "conservação das fontes de água", "conservação da área de produção (solo, água)" e "preservação da vegetação nativa", pois, obtiveram os resultados mais altos dessa instância.

Dada a relação direta das fontes de água e dos solos com a qualidade da água ingerida e da conservação da área natural e de produção com a qualidade de vida dos seres humanos e dos ecossistemas envolvidos localmente, destaca-se, a priori, que os resultados promissores dos indicadores de capital natural do ICV assinalaram uma boa relação entre as famílias rurais do TZS e a natureza que as circunda. Além disso, essa relação sociedade-natureza positiva, de certo modo, reduz a exposição dos indivíduos às situações de vulnerabilidades relacionadas, por exemplo, aos aspectos sanitários, às doenças evitáveis (como respiratórias ou causadas por parasitas e mosquitos que vivem em lugares insalubres) que podem ser causadas pelo descuido e destruição do meio ambiente e podem incidir negativamente sobre outros aspectos da vida.

Todavia, segundo apontam Rambo et al. (2015), existe no TZS uma realidade em que ao mesmo tempo que os indivíduos percebem positivamente a preservação e a conservação dos recursos naturais, a paisagem que se observa diverge dessa percepção. Por exemplo,

Raramente visualiza-se mata ciliar adequada aos parâmetros do Código Florestal Brasileiro ou mesmo áreas de preservação permanente ou reservas legais averbadas (RAMBO et al., 2015, p. 85).

Direcionando-se para análises da terceira instância do índice, a conversão dos meios para realizar funcionamentos está relacionada com a capacidade de uma pessoa atingir diferentes combinações de capitais, estratégias, ações e estados para levar a vida conforme deseja. Tais combinações, de acordo com Sen (2008), compõem-se em um conjunto de vetores de funcionamentos que dão a liberdade para o indivíduo de escolher dentre as vidas que lhe é mais agradável, formando, pois, seu conjunto capacitário.

Conforme Sen $(2008,2010)$, a capacidade é definida a partir de um conjunto de funcionamentos que representam várias combinações alternativas de ações e estados. Essas combinações, como já mencionado, dependem dos capitais acessados por um indivíduo, de suas características sociais e pessoais e das privações a serem destruídas e ultrapassadas.

Se o conjunto de funcionamentos constitui o bem-estar de uma pessoa, a capacidade desta de realizar tais funcionamentos constitui as suas liberdades, ou, nas palavras de Sen (2008, p. 80), "nas oportunidades reais" para alcançar o bem- 
-estar. Esse conjunto de liberdades para realizar outras combinações de escolhas e funcionamentos que estão ao alcance da pessoa, por fim, constitui o conjunto capacitário. É através dele e por meio da liberdade de escolhas que se pode inferir sobre os fins do desenvolvimento humano.

Nesse sentido, a última instância do ICV refletiu a respeito dos efeitos dos processos de desenvolvimento no TZS a partir da análise dos funcionamentos realizados pelas famílias rurais e de seu conjunto capacitário. Com o maior resultado geral $(0,644)$ dentre as três instâncias, con- forme indicado na Tabela 3, a Instância 3 recebeu um critério avaliativo mais abrangente ("médio alto").

O Biograma exposto na Figura 3 ilustra o desempenho de cada um dos oito indicadores do ICV. Como pode ser percebido, o indicador que pior foi avaliado em termos quantitativos e qualitativos referia-se às participações em atividades culturais, relacionado ao capital social.

Todos os indicadores desta instância representaram um funcionamento: estar nutrido, estar saudável, ter emprego, ter renda adequada,

Tabela 3. Índice de Condição de Vida e frequências - Instância 3 e indicadores

\begin{tabular}{llc}
\hline \multicolumn{1}{c}{ Indicadores } & ICV & Frequência \\
\hline Instância 3 & 0,644 & \\
Condições de alimentação e nutrição & 0,748 & 280 \\
Condições de saúde & 0,632 & 280 \\
Permanência dos membros da família no domicílio & 0,876 & 280 \\
Situação econômica & 0,601 & 280 \\
Situação ambiental & 0,584 & 280 \\
Participação em organizações comunitárias & 0,618 & 280 \\
Participação política & 0,597 & 280 \\
Participação em atividades culturais & 0,492 & 280 \\
\hline
\end{tabular}

Nota: Mínimo: 0,000; Máximo: 1,000

Fonte: Elaborada pela autora com base nos dados do SGE (2015).

Figura 3. Biograma da Instância 3

17. Condições de alimentação e nutrição

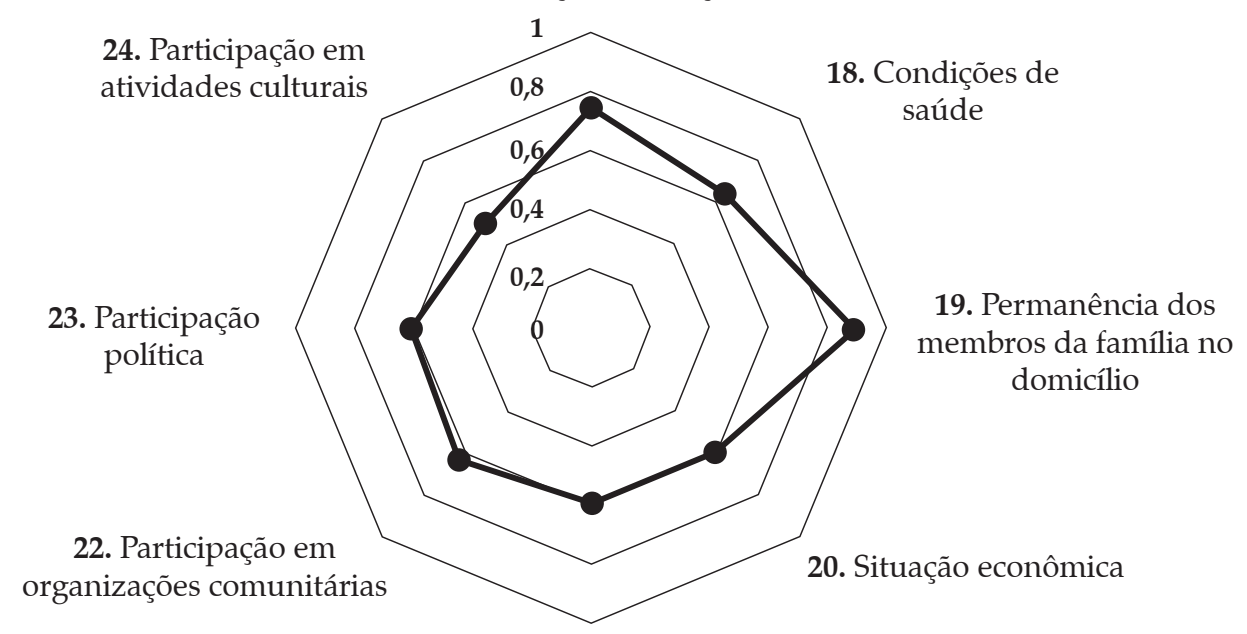

21. Situação ambiental 
estar em harmonia com o meio ambiente, ter participação nas organizações comunitárias, ter participação política e ter participação em atividades culturais. Muitos desses funcionamentos são inegavelmente importantes para o bem-estar de uma pessoa e para livrá-la da pobreza - não apenas em termos monetários, mas, sobretudo, em termos de oportunidades e identidade.

No que diz respeito à fome, não há ameaças à vida apenas quando a alimentação é insuficiente. De acordo com Mayer (1984), se ela for mal constituída o prejuízo pode gerar um efeito dominó. Estar bem nutrido interfere, também, no funcionamento de estar saudável/ter saúde. Poder escolher entre passar fome por opção (religiosa ou pessoal) e não passar fome, justamente por ter liberdade de escolher o que é melhor para si, é o que Sen chama de auferir liberdade.

Melhor nutrição e saúde também estão fortemente relacionados com emprego, educação e renda. Baixos níveis desta última variável podem ser a explicação para altos níveis de analfabetismo, más condições de saúde, fome, subnutrição e desemprego. Analogamente o recíproco se confirma: melhores níveis de educação e saúde podem propiciar níveis de rendas mais proeminentes e qualidade de empregos melhores (SEN, 2010).

A questão da participação cultural pelas sociedades ou comunidades e da manutenção da tradição dentro delas também é relevante nesta análise. Com frequência percebe-se o argumento de que sempre é melhor ser rico e feliz do que pobre e tradicional, como se esses elementos fossem opostos um ao outro. A decisão de sacrificar ou não uma vida tradicional para não se deixar devastar pela pobreza ou morte prematura deve ser respeitado como liberdade humana de escolher o que é melhor para si (SEN, 2010).

Ainda, a participação em atividades culturais facilita a interação social entre a comunidade fortalecendo seus laços e permitindo que cada indivíduo construa sua própria identidade. Sendo assim, sinais negativos nesta dimensão (como percebido na Instância 3) podem refletir em outros aspectos importantes da vida e na expansão das liberdades em geral.
Em síntese, as capacidades e as liberdades de escolha para realizar funcionamentos dependem de e são influenciadas por inter-relações, ou melhor, por "múltiplas liberdades inter-relacionadas" (SEN, 2010, p. 77). Cada indicador analisado na Instância 3 possuía uma relação entre si, fosse direta ou não. Assim, boas indicações em relação à situação ambiental, por exemplo, puderam indicar, também, boas condições de saúde.

O que os dados da Instância 3 do ICV apontaram foi a existência de um cenário favorável no que diz respeito aos efeitos do desenvolvimento no território, sobretudo na escala humana. A percepção das famílias para os indicadores foi preponderantemente boa. Os funcionamentos mais básicos como ter saúde, estar nutrido, ter renda e estar em harmonia com o meio ambiente foram realizados. Os indicadores de participação política e em organizações comunitárias também tiveram percepções majoritariamente boas. Os funcionamentos relacionados a eles podem propiciar outros funcionamentos mais complexos como ter respeito próprio, ter consciência de sua identidade e estar ciente de seu papel na sociedade.

Na Figura 4, o Biograma mostra o desempenho das três instâncias para a totalidade da amostra. Como percebido, a Instância três foi a melhor delas e a Instância 1, a pior.

A análise dos funcionamentos e do conjunto capacitário (Instância 3), enquanto efeitos do desenvolvimento humano no TZS, portanto, permitiu inferir sobre o quão exposta a população estava às diversas formas de privação de liberdade. Mesmo que não tenham sido detectadas situações de subnutrição e pobreza extrema, por exemplo, alguns resultados (sobretudo da Instância 1) deram indícios de possíveis carências de oportunidades básicas que comprometem a longevidade da comunidade, família e/ou indivíduo e priva-os de conduzir suas vidas de maneira adequada e desejável (SEN, 2010).

Qualquer movimento, operação ou intervenção que possa ser feito para evitar a privação de capacidades e liberdades, tanto em nível indi- 
Figura 4. Biograma do ICV final

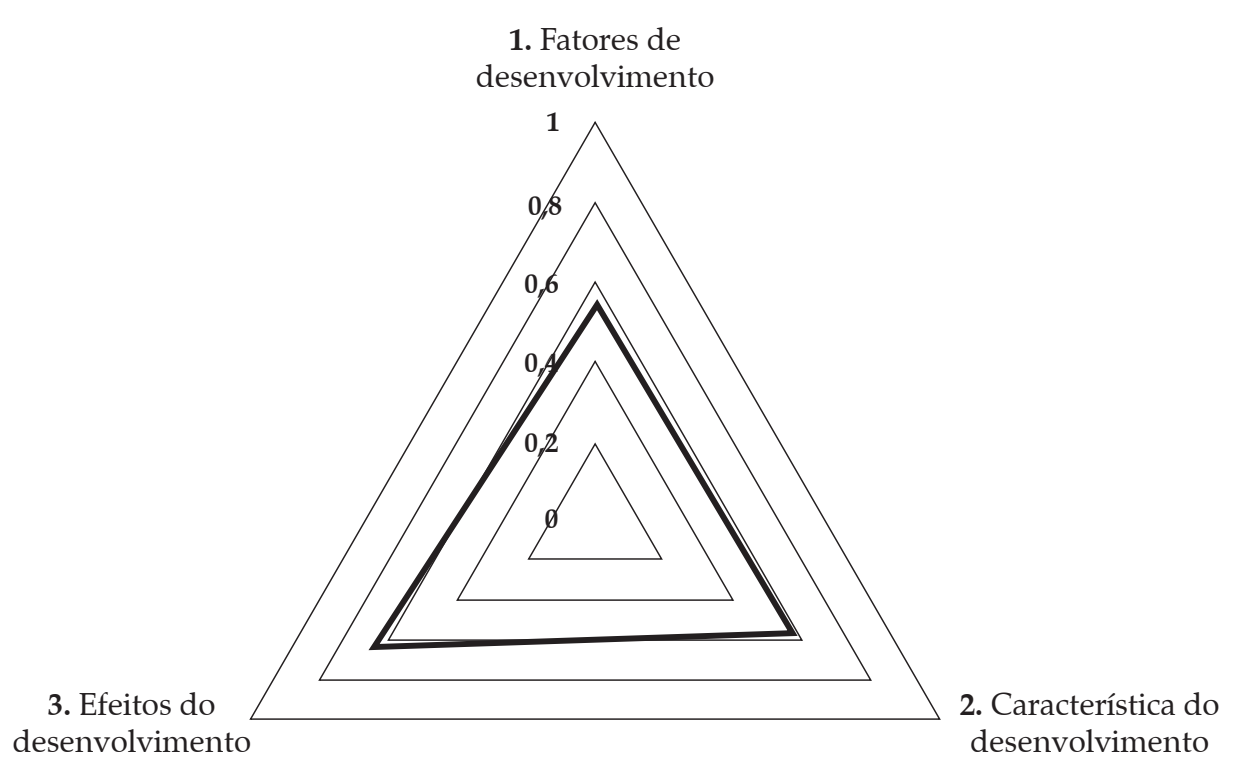

Fonte: Elaborado pela autora com base nos dados do SGE (2015).

vidual como em nível governamental e institucional, são favoráveis para evitar a pobreza de oportunidades. Nesse contexto, as políticas são indubitavelmente elementares. Mas a condição de agente do indivíduo na busca pela totalidade de seus objetivos e valores (estejam ou não relacionados à promoção do seu próprio bem-estar) ${ }^{7}$ também não pode ser dispensada.

Com base nisso, os dados gerais do Índice de Condição de Vida do Território Rural Zona Sul puderam inferir que, em termos de funcionamentos realizados e tendo por base as próprias percepções das famílias rurais dos domicílios estudados, essas não se mostraram expostas às situações críticas de vulnerabilidade e de pobreza rural. Apesar das privações afirmadas, sobretudo na Instância 1 (por exemplo, no acesso às políticas públicas e ao crédito), é inegável que desde a última década o Brasil todo vem expandindo o acesso da população total (e dos grupos sociais diversos que a compõe) a uma gama de oportunidades variadas ligadas a diversos

7. No livro Desigualdade reexaminada de Sen (2008) é discutida a possibilidade de objetivos e valores de uma pessoa não estarem relacionados diretamente ao seu próprio bem-estar. capitais. ${ }^{8}$ Ou seja, não é só na desigualdade em termos monetários que a melhora vem se prevalecendo, mas, essencialmente na desigualdade de oportunidades.

Porém, não se pode deixar de considerar que a percepção positiva das famílias acerca de suas condições de vida, apesar das privações constatadas no acesso aos meios importantes, pode, justamente, estar relacionada com situações de vulnerabilidade e fragilidade em razão de essas famílias estarem, possivelmente, imersas em uma acomodação resignada (e aqui evidencia-se a limitação do ICV em refletir, verdadeiramente, as condições de vida). Segundo Sen (1993), um indivíduo pode levar uma vida muito pobre, mas aceitá-la de forma silenciosa e resignada. Acostumado com a situação de privações pode não persistir em queixas e, inclusive, tentar extrair prazeres de coisas mínimas. Assim, as privações podem não ser captadas por esta pessoa.

8. Por exemplo: financeiro: políticas de transferência de renda, políticas de acesso ao crédito, políticas de acesso aos mercados; humano: expansão de cursos técnicos e profissionalizantes, expansão das cotas nas universidades, criação de empregos, criação de leis contra violências diversas; social: programas de inclusão social. 
Essa questão sobre acomodação resignada traz reflexões sobre o que a realidade mostrava e o que os indivíduos percebiam a partir dela. O fato de o ICV se propor refletir as percepções dos indivíduos sobre eles mesmos mostra uma limitação do próprio índice, uma vez que, como já dito, essas percepções podem não estar em consonância com a real condição de vida dos agentes entrevistados. Todavia, essa limitação não invalida a análise feita e ainda reforça a adequabilidade de o ICV ser usado para análises macrossociais de políticas públicas.

\section{Conclusões}

Pobreza e vulnerabilidade não podem ser avaliadas apenas em termos monetários (de renda e riqueza), mas, sobretudo, em termos de liberdades e oportunidades. Conforme a UNDP (2014), pobreza e vulnerabilidade estão multidimensionalmente interligadas e reforçam-se uma a outra, mas não são sinônimos.

A vulnerabilidade é um aspecto importante da pobreza e inerente ao pobre, uma vez que seus leques/portfólios de capitais e de capacidades sofrem deprivações por circunstâncias diversas. O pobre quase sempre é impedido de obter um conjunto capacitário alargado, o que significa dizer que com frequência apresenta deficiências em muitas áreas, como educação, saúde e alimentação (UNDP, 2014). Estar exposto à vulnerabilidade não significa necessariamente estar propenso à pobreza. Mas, para a pessoa que já está imersa nela, a vulnerabilidade pode intensificá-la e gerar cada vez mais privações.

Os resultados do ICV em todas as análises inferiram que em termos de recursos e capitais acessados, isto é, os meios para alcançar o bem-estar e condições de vida adequadas e desejáveis (Instância 1), a percepção das famílias foi pior. Muitos capitais essenciais para a sustentação de um padrão de vida adequado e para a reprodução social, especialmente para as pessoas que residem no meio rural, como acesso ao crédito, políticas públicas e programas do governo, assistência técnica, foram dificilmente acessados ou acessados com muitas complicações, o que, por si só, já evidencia a existência de privações que deveriam ser superadas. Tais privações reduzem as capacitações dos indivíduos e restringem suas liberdades de alcançar resultados desejáveis. Uma vez que o papel das primeiras é justamente propiciar a minimização das consequências negativas de choques, tendências e vulnerabilidades diversas a partir do alargamento das capacidades (com base no acesso aos capitais e do uso e da posse deles, por exemplo), qualquer obstáculo neste processo pode gerar um impedimento e/ou uma dificuldade na proteção e na garantia dos funcionamentos individuais quando as circunstâncias mostrarem deterioração (UNDP, 2014). E isso foi constatado ao longo da pesquisa, por exemplo, quando ficou evidente, na Instância 1, as dificuldades no acesso ao crédito e políticas públicas, que se refletiram em percepções medianas a respeito da situação da renda (Instância 3). Por esta razão, e como já foi explorado minimamente ao longo do artigo, uma melhor efetividade nas políticas públicas poderia ser (apenas) um dos meios para reduzir as privações existentes no TZS que impediam e/ou dificultam a elevação do bem-estar das famílias rurais.

Ao ser analisada a conversão dos meios para os fins do desenvolvimento humano (Instância 2), isto é, o uso dos capitais, recursos e oportunidades e a arquitetura de estratégias de vida, a percepção das famílias sobre suas condições de vida foi um pouco melhor. Lidar com a pobreza e com as situações de vulnerabilidade (as quais não estavam apenas relacionados à desigualdade no acesso aos recursos) pode ter sido consequência da capacidade de agência dos indivíduos em diversificarem, em diversos graus, o uso dos meios acessados e da habilidade de lidar com riscos e eventos adversos. Pôde-se supor, ainda, que as melhores percepções nesta instância (e também na Instância 3) foram geradas por uma certa satisfação dos agricultores sobre suas condições de vida. Isto é, embora a renda, a escolaridade e os cuidados com os recursos naturais, por exemplo, tenham de fato mostrado alguma fragilidade, para os/as entrevistados/ entrevistadas tais situações eram suficientes para o tipo de rotina que possuíam. 
Como já mencionado, foi corroborada, sim, a existência de sérias privações que de maneira evidente podem ter reduzido, impedido ou dificultado o aumento do bem-estar, além de indicar situações concretas e/ou potenciais de vulnerabilidade. Estar imerso nessa conjuntura pode não tornar o TZS um território, de fato, pobre em termos monetários, mas, em certa medida, o torna um território de população vulnerável e propensa à pobreza de oportunidades (principalmente a parcela rural), o que vai ao encontro das reflexões trazidas no parágrafo anterior.

O Índice de Condições de Vida salientou o TZS como um território com privações no acesso aos recursos e, por esta razão, merece maior atenção na pauta de desenvolvimento. Mas deve-se destacar também que alguns indicadores (como diversificação da produção e diversificação da renda, sobretudo) apontaram que os próprios indivíduos, ao não buscarem alternativas auxiliares, expuseram-se, eles mesmos, a alguns tipos de vulnerabilidade que, no médio prazo, podem refletir na não expansão do bem-estar e na redução de suas condições de vida.

Portanto, reflete-se que uma ação mais integrada entre o Estado, as instituições e as comunidades rurais possa ser um caminho que assegure uma coesão social mais sólida e efetiva. Altas capacitações permitem que os indivíduos sejam capazes de fazer escolhas e isto significa liberdade para agir. Porém, para que isto seja possível é fundamental que os indivíduos estejam livres de tudo aquilo que possa inibir suas habilidades de agir (UNDP, 2014). Por esta razão, um cenário de maior integração entre os atores sociais do TZS poderia permitir maior empoderamento para que as pessoas possam adquirir mais resiliência, de forma a obter oportunidade de alcançar a vida que elas mesmas valorizam.

\section{Referências}

ANDRADE, S. M. et al. Condições de vida e mortalidade infantil no Estado do Paraná, Brasil, 1997/2001. Caderno Saúde Pública, v. 22, n. 01, 2006. Disponível em: < http:// www.scielo.br/pdf/csp/v22n1/19.pdf>. Acesso em: 09 jan. 2017.

BRASIL. Ministérios do Desenvolvimento Agrário. Elaboração da proposta do Índice de Condições de Vida para aplicação nos territórios rurais (ICV-Territórios Rurais). Relatório com a proposição do Índice de Condição de Vida. SDT. Secretaria de Desenvolvimento Territorial. Ministérios do Desenvolvimento Agrário, 2007.

. Sistema de gestão estratégica: índice de condição de vida. Brasília: MDA/SDT, 2011.

CHAMBERS, R. e CONWAY, G. Sustainable rural livelihoods: practical concepts for the 21st century. [S.1.], 1991. (IDS Discussion Paper, 296). Disponível em: $<$ https://www.ids.ac.uk/files/Dp296.pdf>. Acesso em: 19 nov. 2014.

COMIM, F, e BAGOLIN, I. P. Aspectos qualitativos da pobreza no Rio Grande do Sul. Ensaios FEE, Porto Alegre, v. 23, n. especial, 2002. Disponível em: <http:// cdn.fee.tche.br/eeg/1/mesa_4_comim_bagolin.pdf $>$. Acesso em: 20 ago. 2015.

DACOSTA,R.F.R.eCOSTA, G.C. Pobresnocampo,ricos na cidade? Uma análise multidimensional da pobreza. Revista de Economia e Sociologia Rural, Piracicaba, v. 54, n. 3, 2016. Disponível em: <http://www.scielo.br/pdf/ resr/v54n3/1806-9479-resr-54-03-00537.pdf>. Acesso em: 09 jan. 2017.

ELLIS, F. Rural livelihoods and diversity in developing countries. UK: Oxford, 2000.

IBGE - Instituto Brasileiro de Geografia e Estatística. Pesquisa nacional por amostra de domicílios: volume Brasil: unidades da federação. Rio de Janeiro, 2014. Disponível em: $\quad<\mathrm{http}: / /$ www.ibge.gov.br/home/estatistica/ populacao/trabalhoerendimento/pnad2014/brasil_ defaultxls_unidades.shtm >. Acesso em: 19 nov. 2015.

IPEA/Fundação João Pinheiro. Definição e metodologia de cálculo dos indicadores e indices de desenvolvimento humano e condições de vida. Rio do Janeiro: IPEA, 1999.

KAGEYAMA, A. Pluriatividade e ruralidade: aspectos metodológicos. Economia Aplicada, São Paulo, v. 2, n. 3, 1998.

. e HOFFMANN, R. Pobreza no Brasil: uma perspectiva multidimensional. São Paulo: Campinas, Revista Economia e Sociedade, v. 15, n. 1, 2006. Disponível em: < http://periodicos.sbu.unicamp.br/ojs/index.php/ ecos/article/view/8642922/10492>. Acesso em: 09 jan. 2017.

JODELET, D. Représentations sociales: un domaine en expansion. In: JODELET, D. (Ed.). Les représentations 
sociales. Tradução: Tarso Bonilha Mazzotti. Revisão Técnica: Alda Judith Alves Mazzotti. Paris: PUF, 1993, p. 31-61.

MERLEAU-PONTY, M. Fenomenologia da percepção. 3. ed. São Paulo: Martins Fontes, 2006.

MAYER, A. Prefácio à nona edição. In: CASTRO, J. Geografia da fome: o dilema brasileiro: pão ou aço. Rio de Janeiro: Antares, 1984, p. 5-11.

MOREIRA, R. C. et al. Políticas públicas, distribuição de renda e pobreza no meio rural brasileiro no período de 1995 a 2005. Revista de Economia e Sociologia Rural, Piracicaba, v. 47, n. 04, 2009. Disponível em: < http:// www.scielo.br/pdf/resr/v47n4/a06v47n4.pdf>. Acesso em: 09 jan. 2017.

MOSCOVICI, S. Representações sociais: investigações em psicologia social. Rio de Janeiro: Vozes, 2003.

OLIVEIRA, L. L. S. Idese: uma análise sobre o Índice de Desenvolvimento Socioeconômico do Rio Grande doSul. Texto para Discussão FEE no 115, Porto Alegre: FEE, 2013. Disponível em: <http://www.fee.rs.gov.br/wp-content/ uploads/2014/07/20140730idese_-uma-analise-sobre-oindice-de-desenvolvimento-socioeconomico-do-riogrande-do-sul.pdf>. Acesso em: 09 jan. 2017.

PEREIRA, M. de A., SOUZA, M. e SCHNEIDER, S. Meios de vida e livelihoods: aproximações e diferenças conceituais. Revista IDeAS, [S.1.], v. 4, n. 1, 2010. Disponível em: <http://www.ufrgs.br/pgdr/ publicacoes/producaotextual/Sergio $\% 20$ Schneider/ pereira-marcio-de-araujo-souza-marcelino-e-schneidersergio-meios-de-vida-e-livelihoods-aproximacoes-ediferencas-conceituais-revista-ideas-v-4-n-1-p-203-224jun-jul-2010>. Acesso em: 20 mar. 2016.

PERONDI, M. A. e SCHNEIDER, S. Bases teóricas da abordagem de diversificação dos meios de vida. Redes, Santa Cruz do Sul, v. 17, n. 2, 2012.

RAMBO, A. G et al. Território e desenvolvimento na escala humana: condições de vida e gestão territorial no Sul do Rio Grande do Sul. Apresentação Oral. Congresso SOBER - Sociedade Brasileira de Economia, Administração e Sociologia Rural. Vitória, 2012.
. et al. O Índice de Condições de Vida (ICV): construindo metodologias de análise e avaliação de dinâmicas territoriais do desenvolvimento rural. Revista em Gestão, Inovação e Sustentabilidade, Brasília, v. 1, n. 1, p. 68-94, 2015.

SCHNEIDER et al. Relatório analítico célula de acompanhamento e informação - CAI - Zona Sul do estado do Rio Grande do Sul. Projeto de Pesquisa e Extensão Tecnológica. MDA/SDT/CNP, 2012.

SCHNEIDER, S. e FREITAS, T. Qualidade de vida, diversificação e desenvolvimento: referências práticas para análise do bem estar no meio rural. Olhares Sociais, [S.1.], v. 2, p. 121-142, 2013. Disponível em: <http:// www.ufrgs.br/pgdr/publicacoes/producaotextual/ Sergio \% 20Schneider/schneider-s-freitas-d-tqualidade-de-vida-diversificacao-e-desenvolvimentoreferencias-praticas-para-analise-do-bemestar-nomeio-rural-olhares-sociais-v-2-p-121-2013>. Acesso em: 20 mar. 2016.

SEN, A. Desigualdade reexaminada. 2. ed. Rio de Janeiro: Record, 2008.

- Desenvolvimento como liberdade. São Paulo: Companhia das Letras, 2010.

- O desenvolvimento como expansão de capacidades.LuaNova,n.28-29,SãoPaulo,1993.Disponível em: <http://www.scielo.br/scielo.php?script=sci_arttex t\&pid $=$ S0102-64451993000100016 $>$. Acesso em: 20 mar. 2016.

SOARES, S. S. D. Metodologia para estabelecer a linha de pobreza: objetivas, subjetivas, relativas $\mathrm{e}$ multidimensionais. Rio de Janeiro: IPEA, 2009. (Texto para discussão, 1381). Disponível em: <http://www. ipea.gov.br/portal/images/stories/PDFs/TDs/td_1381. pdf $>$. Acesso em: 28 nov. 2015.

UNDP - United Nations Develipment Programme. Human development report 2014. Sustaining human progress: reducing vulnerabilities and building resilience. New York, 2014. Disponível em: <http:// www.pnud.org.br/arquivos/rdh2014.pdf $>$. Acesso em: 20 nov. 2015. 